\title{
Post-internet Verfremdung
}

\author{
Helena Björk
}

\section{Prologue}

14-year-old (about their work): "I suppose I could upload this on Instagram and write something deep."

Me (curiously): "How do you write something deep on Instagram?"

14-year-old: "Well, it's hard to explain.... But none of the usual stuff, and no hashtags."

I work as an art teacher with students between the age of 13 to 15 in a lower secondary school in Porvoo, Finland. The internet with its imagery is ever present in my work, in constantly changing ways. Trending memes pop up in digital collages and analogue drawings, inspirational quotes circulate and boost a new interest in cursive writing, and the other day I learned that galaxies are no longer popular. Even speech is sprinkled with internet references. Teenagers speak in hashtags, have learned some concepts from memes and sometimes appear to have minds that operate with GIF-imagery. Their habits are a constant reminder of the "Internet state of mind" (Scherpe, 2011, para 37), where references and formats abound, and have everything to do with the physical world. When I

H. Björk (凶)

Lyceiparkens skola, Porvoo, Finland

(C) The Author(s) 2021

K. Tavin et al. (eds.), Post-Digital, Post-Internet Art and Education, Palgrave Studies in Educational Futures, https://doi.org/10.1007/978-3-030-73770-2_17 
mention that we will be working with clay, one teenager wants to recreate a famous scene from the movie Ghost (1990) with Demi Moore and Patrick Swayze by the pottery wheel. A classmate is unfamiliar with it and so the girl shows him what it's all about-but it turns out she only knows the scene from a popular GIF and hasn't seen the movie itself.

In this context the internet is a globally present entity, a source of inspiration and an arena that interacts with all other elements of life. In the spring of 2020, it became even more prominent as we found ourselves in the midst of a global pandemic and school moved online. With a larger proportion of digital assignments, art teachers may have gained more insights into online visual cultures than ever before. These days, the natural habitat of a short video montage appears to be social media, as my teenage students combine what they have learned about juxtaposing video clips with things they have learned from interacting with each other on TikTok. This is what it inevitably looks like when Sergei Eisenstein's Battleship Potemkin (1925) meets moving image that has become accessible to everyone and ingrained in everyday life online. From the point of view of art education, the internet is full of visual cultures, pop culture, and remixes. It influences what kind of images to create, how to create them and why. Social media forms our behavior by offering rewards in the form of likes, but the internet is also a site of more complex learning and participation that has a lot of yet unseen potential.

\section{INTRODUCTION}

In this chapter, I examine visual culture on the platform of Instagram as a form of performance. Framed by the standard formats-or a deliberate choice to deviate from them-aestheticized in one way or another, and directed at an audience an Instagram post or an entire account has a lot in common with theatre. Yet, the audience seems unaware of the construction on display, despite hands-on experience of editing images and creating posts.

To explore a perspective which is intriguing from an aesthetic as well as educational point of view, this chapter looks closely at Bertolt Brecht's thoughts on theatre. I will focus particularly on the notion of Verfremdungseffekt, which is also commonly known, in English, as the alienation effect. Brecht's aim was to inspire critical reflection in the audience with the help of commentary or visible technical devices that broke the illusion of the play. His emphasis on society provides an interesting starting point 
for an analysis of today's visual culture (Tavin \& Tervo, 2018). Brecht (1982b, 1982d, 1982f) also frequently addressed the educational aspects of art, which makes him even more significant for art educators.

Brechtian theatre is here seen as a framework to understand how we operate as followers on social media, to reach the stage of "something deep" sought by the 14-year-old in my classroom, and beyond. It could also provide a runway for the critical imagination, or ways to subvert and play with social media. For art educators, Brecht's thoughts on theatre could offer an eye-opening perspective in this age of highly participatory visual cultures as well as concrete tools that are engaging on a more than cerebral level. As we nurture creativity and criticality alongside visual skills in classrooms across the world, Brecht's concepts may resonate with the very core of our work.

\section{Instagram as an Arena for Artistic Exploration}

Social media have been around for more than a decade, and helped form our lives in many ways. So far, they have been the subject of some studies, many of which focus on Facebook and rely on self-reporting (which is not entirely reliable). Some studies have been conducted around the visual language of specific groups while others have examined the connection between social media and well-being, but much remains yet to be done (Brown, 2018).

Instagram is a highly visual social media platform owned by Facebook Inc. that allows users to upload photos or a clip of moving image of up to 60 seconds. With its filters to quickly edit photographs or create a mood, the app was originally developed for photo sharing and to compensate for the poor quality of smartphone cameras. In contrast to Twitter, a very text based social medium, Instagram is primarily driven by images. Unlike its close relative Facebook, which typically connects friends, family, and acquaintances, Instagram networks are more loosely based and an account can attract followers based on its content, much like a blog. Images are accompanied by captions and often hashtags, but the simple interface of Instagram is not designed for sharing events, interacting with specific groups or discussing news articles. Indeed, representation of "the real world" seems to be the main focus and the tools primarily visual. These reasons make Instagram a particularly interesting social medium to explore from the point of view of visual literacy. 
A popular visual pastime can also have a negative impact on the lives of individuals. The British report, \#StatusOfMind, from The Royal Society of Public Health (2017) and the Young Health Movement examined the positive and negative effects of social media on young people's health in 2017. The report studied social media platforms according to their impact on young people and concluded that Instagram and Snapchat were the most detrimental to young people's mental health and well-being. One of the report's recommendations, supported by $68 \%$ of young people, was for social media platforms to highlight when images have been digitally manipulated (Royal Society for Public Health, 2017). While this idea is guided by good intentions, it doesn't promote visual literacy to a great degree. Aspects of photography such as choices of subject matter, camera angles, and cropping will still remain. The report does, however, suggest that images have a strong impact on well-being.

When Instagram started gaining popularity among influencers, and the thought of a curated feed spread among users, InstaStories were launched as a way to publish content that remained online for 24 hours. This way, users did not have to face the problem of whether a moment was special enough-a problem that was actually addressed by the founder of Instagram himself-but had the opportunity to casually upload images and video with text. Originally a Snapchat format, the new feature was said to encourage more "authentic" material (Wagner, 2018).

Arguably the most widely noted art project on Instagram to date is Amalia Ulman's (2014) Excellences \& Perfections. The artist launched the project in 2014 and posted images with captions according to a manuscript over a four-month period. Ulman started her three-part social media performance with an image that stated Excellences \& Perfections, Part 1, much like a Brechtian title on stage. By a strategic use of popular hashtags, she quickly gained many followers.

Ulman's Instagram performance told a mainstream story of a girl who moves to Los Angeles with many clichéd elements. She first works as a model, but finding herself out of money she finds herself a rich lover. Images speak of a cute girl, of a glamorous lifestyle that included plastic surgery, drugs, recovery, and the healthy lifestyle that followed. Everything was executed according to a manuscript by the artist who would sneak into luxury hotels for the right kind of environment, or to buy clothes for her character only to return them. During this time, Ulman only became her character for the photos and reportedly spent a lot of time in the forest (Ulman, 2020). 
The nature of the project could have been obvious to anyone who suspected staged photographs or knew the artist, but the revelation that the material was not a documentation of an actual life of someone came as a complete surprise to the followers of the account and even sparked outrage. The artist herself described the reactions:

When I revealed that my Instagram character was a creation, some of my followers were angry. A lot had left sexist comments on my profile. The work was holding up a mirror and they did not like what they saw. (Ulman, 2020, para. 13)

In other interviews Ulman has explained the background of her project:

The idea was to bring fiction to a platform that has been designed for supposedly 'authentic' behavior, interactions and content. The intention was to prove how easy an audience can be manipulated through the use of mainstream archetypes and characters they've seen before. (Gavin, 2014, para. 1)

It was precisely by participating in mainstream imagery, or what Ulman has called an interest in middlebrow aesthetics, that the project gained large numbers of followers and attention.

In a review of Ulman's show with other works, Tess Edmonson (2015) notes, "In performing the mainstream, Ulman works to uncouple it from the ahistorical normalcy it enjoys" (para. 4). This observation comes across as a very Brechtian interpretation of Ulman's projects and how they operate; making the familiar look strange, albeit in subtle ways. On a further note, taste seems to be an important element of Excellences \& Perfections which Edmondson describes as "a careful study of how taste structures and mediates expressions of female experience" (para. 3).

The project showed what we read into social media and how willing we are to believe what we see to be "authentic." Since 2014, Excellences \& Perfections has attracted the attention of the New Museum in New York and Whitechapel Gallery in London who have exhibited Ulman's work, as well as Tate Modern who featured documentation of the performance in the show Performing for the Camera. Institutional attention could mean many things, but in this particular case Ulman's project seems to have used Instagram's visual language for critical purposes in a unique and 
pioneering way. The museums may have recognized what was the first of many artistic explorations of social media.

While social media keep evolving with visual trends among users and a wide range of opportunities for advertisers, we seem to be less imaginative in the role of the audience. The reactions to Amalia Ulman's project suggest that a critical gaze is not yet commonplace, and that the thought of a playful experiment, art project, or blurring of reality and fiction seems to upset many people. As creators of content, we might see things differently however, and learn to play with subject matter, representation, and levels of meaning. From my vantage point in the classroom, the step comes across as quite effortless. While teenagers may condemn "fake" content on social media, they seem to quickly switch to an intuitive understanding of Ulman's intentions and a keenness to experiment with fiction themselves.

Bertolt Brecht's theatre can provide a useful frame of reference for Ulman's Instagram performance and further experiments in the classroom, or elsewhere. In my teaching practice I have introduced Excellences o Perfections to teenagers as well as art education students and then given them the assignment of creating fiction on Instagram. Alter egos have ranged from a silly twelve-year-old and an obsessively sporty teenager to a spiritual leader and an overly eager art teacher. In an educational context the question would be: can tweak our experience with the help of creative ways of operating within the platform?

\section{VERFREMdUNGSEFFEKT AND THE THEATRE}

As stated earlier, Bertolt Brecht was a German playwright and poet who radically broke traditions of drama, but also wrote extensively about the social and political relevance of theatre. ${ }^{1}$ In the essay, The Modern Theatre is the Epic Theatre (1982d), Brecht lays out the characteristics that distinguish what he called the epic theatre. He criticizes the majority of plays of his time and especially opera for being what he calls fodder for the entertainment apparatus, or art based on "the culinary principle." As he lays out the characteristics separating epic theatre from dramatic theatre, it becomes clear that Brecht is aiming at evoking critical reflection in the audience (1982d). The spectator in dramatic theatre relates to a stage situation as if an invisible fourth wall around the stage-the one between the audience and the actors - existed. The purpose of the drama is to provide the spectator with sensations, an involvement through identification and 
an experience by means of linear development and succession from one scene to another. Epic theatre, in contrast, emphasizes narrative in favor of plot, turning the spectator into an observer and arousing a capacity for action by what is described as breaking the fourth wall (Brecht, 1982d).

Brecht gives many examples of how the epic theatre can affect the viewer: "The text had to be neither moralizing nor sentimental, but to put moralizing or sentimentality on view. Equally important was the spoken word and the written word (of the titles). Reading seems to encourage the audience to adopt the most natural attitude toward the work." (Brecht, $1982 \mathrm{dd}$, p. 38) The written titles Brecht refers to are titles to each scene of the play. As written elements on stage they form a type of commentary to the drama. Brecht further explains the significance of the titles in Notes to the Threepenny Opera:

The screens on which the titles of each scene are projected are a primitive attempt at literarizing the theatre. This literarization of the theatre needs to be developed to the utmost degree, as in general does the literarizing of all public occasions. [...] Literarizing entails punctuating 'representation, with 'formulation'; gives the theatre the possibility of making contact with other institutions for intellectual activities. (Brecht, 1982c, p. 43)

Having the titles of the scene on stage is opposed to the idea of everything being contained within the drama. The spectator is made to think about a subject rather than thinking within the confines of a subject. Punctuating representation means precisely this: while the illusion of the play can exist, an element of reflection is added to the experience of the viewer. Taking this idea to Instagram could provide new ways of relating to the medium where it can play the same role as before, but with added layers of meaning.

What emerges from Brecht's thoughts on Verfremdung is a sense of nurturing the minds of the audiences. This does not mean that emotions are denied, but rather seen as one part of the experience that also involves the intellect. Being completely absorbed by the illusion of the play is to be avoided at all costs. In a similar way, Instagram offers glimpses into other people's lives and it might be easy to imagine what their vacation or dinner was like, without a single reminder that we're actually looking at an image: a result of choices.

What is the role of Verfremdung in the relationship between art education and post-internet imagery? Some years ago, in 2015, I had the 
chance to work together with a drama teacher on a play. A group of teenagers wrote a manuscript about two friends who drifted in different directions, about misunderstandings and rumors that affected their lives. A group that had chosen art class had the freedom to work on any visual design for the play together with me. Among other things, the teenagers created Instagram accounts for the main characters that commented on the plot and displayed them on a large screen on stage. The audience thus experienced both dialogue, musical numbers, and written text with still images. One Instagram post stated "Maybe I was born to be sad" in white letters on a gloomy, black background, much like Amalia Ulman's title to Excellences \& Perfections. The group who created the material had fun experimenting with clichés and exaggerated self-pity, which has led me to believe that teenagers are both self-aware and perceptive in ways that could hold the potential for a whole new relationship to social media that adults might learn from.

\section{The Concept of Verfremdung}

Brecht's different techniques, such as projected titles on stage, were means to achieve the Verfremdungseffekt. On the note of these titles and their use as an artistic strategy, Brecht (1982b) emphasizes that they are by no means extras or mechanical aids. The purpose of titles on stage is not to help the spectator but to block a complete empathy with the characters on stage. Their impact is indirect but crucial in preventing the spectator from being carried away, and this is what makes them an organic part of the work of art.

Brecht developed the notion of Verfremdungseffekt in order to present a set of concrete techniques - projected titles being one of them-for the epic theatre. In John Willett's English translation of Brecht's texts on theatre the term alienation can either refer to the term Entfremdung as used by Hegel (1977) and Marx (1964) and brought up by Brecht in early texts, or the term Verfremdung, which was later coined by Brecht himself (Brecht, 1982f, p. 76). What seems to have sparked Brecht's use of the term Verfremdung was a visit to Moscow in May 1935, where Brecht witnessed a performance by Mei Lanfang and his company.

It is important to note that the English word alienation is widely connected to Marx but also quite commonly used for Brecht's Verfremdung. While not entirely unrelated concepts, the German language maintains a clearer difference between the two. Peter Brooker (1998) 
describes other ways in which the term Verfremdung has been dealt with in the English language:

Brecht's term [Verfremdung] has been variously translated 'alienation', 'estrangement', 'éloignement', 'distanciation' and 'defamiliarisation'. As he described it, it employed elements of stage design, music and lighting as well as a gestic acting style in a conscious - and in some ways self-conscious - attempt to historicize characters and events. (p. 62)

Verfremdung has also been connected to the Russian avant-garde and the concept of "priem ostrannenija" or "making strange" in literature. Willett (1982a) assumes that Verfremdung is a direct translation of this term, while Peter Brooker (1998) sees Verfremdung as something broader with a social and political impact. Essentially, the purpose is to make members of the audience see their situation clearly and not only draw attention to the art itself.

Michael Patterson (1994) has a similar take on Verfremdung in a text on the legacy of Brecht. With reference to Brooker, he also sees a problem with the English term alienation in that it implies a much less nuanced experience "that audiences should become either antagonized by the performance or detached from the stage action to the point of boredom" (p. 274).

It appears that Verfremdung has broad connotations and a particularly strong societal emphasis. Whether seen as an artistic strategy or a societal one, Verfremdung aims at making the audience see through the customs and habits of mind which constitute ideology. Making the familiar strange is politically significant in relation to the themes at hand, but the means to achieve it are artistic (Brooker, 1998). Verfremdung, it appears, allows a rich range of emotions and reflection.

In this chapter, I have chosen to use the German term Verfremdung rather than a term like alienation or estrangement in order to remain true to the very specific type of alienation that it refers to. In a context where the aim is to examine performativity on Instagram there is also a real risk of confusion. For example, alienation could refer to a distance to immediate experiences that a constant need for representation or \#fomo (fear of missing out) can create. There is also a point to be made about aesthetic choices in the medium. Verfremdung, therefore, as a primarily theatrical rather than societal term, seems to justify itself as it presents unforeseen possibilities for a visual platform with wide audiences. Teenagers, 
in particular, can be both insightful and inventive when presented with the possibility of Verfremdung.

\section{From Representation to Commentary}

In the essay The Street Scene: A Basic Model for an Epic Theatre, Brecht (1982e) lays out the characteristics of epic theatre and discusses Verfremdung with the help of an example: an event taking place on a street corner. A motor accident occurs, followed by a recap of the events by witnesses, but here Brecht stresses that the actor portraying the events should not be too perfect and should not transform into the people involved in it. He later describes the Verfremdung: "What is involved here is, briefly, a technique of taking the human social incidents to be portrayed and labeling them as something striking, something that calls for explanation, is not to be taken for granted, not just natural" (1982e, p. 125).

Brecht's reflections on acting technique bring to mind the artistic practice of Andrea Fraser. In the spirit of institutional critique, her performance Museum Highlights (2005) mimics institutional language, exaggerating the manners of a guided tour that creates a mystical aura around artworks. By ridiculing this convention, Fraser in fact achieves a Brechtian Verfremdung. Her performances aim at critically exposing how the art world operates, but interpreted with the help of Brecht, this criticality is not only hers but something that her works inspire in the audience. This is what one might hope for if Verfremdung is applied to Instagram: that a critical and playful attitude belongs to both sender and receiver. Exposing how social media works, how we as users operate and how we react to the content we see is quite another thing than turning one's back on these platforms altogether. To work like Andrea Fraser would mean to make fun of the system and ourselves, from within. Brecht's acting technique, as described in the example with the accident, could mean that the narrator of an Instagram post looks at creating it as something striking that calls for explanation.

Brecht often underlines the idea of Verfremdung as necessary to all understanding of the world. When something appears "the most obvious thing in the world" it no longer calls for explanation or a desire to understand. To Brecht, this is giving up on trying to understand the world (Brecht, 1982a, p. 71). On a platform like Instagram, Verfremdung could mean a certain freedom from being carried away or an attempt to understand motives, behaviors, and reactions-while being engaged in it all. If 
Instagram and its typical content are found to be detrimental to young people's mental health, then we as art educators could approach the problem in different ways: by hoping to see warnings attached to images, nurturing greater awareness among users or by imaginatively employing artistic techniques such as Verfremdung in images and text. Brechtian theatre might seem like an advanced reference for schoolchildren, but in my work over the past few years I have become convinced that his written titles on stage are in fact a forefather of today's meme culture. When presented with the possibility of creating classical art memes, 13 year olds come up with hilarious commentary to famous paintings, as if working in a language they are fluent in. The step from everyday use of social media to artistic experimenting has never been awkward. Fiction, exaggeration, and commentary come naturally after an introduction and don't even require much encouragement.

Working creatively with ways that become an integral part of the experience is both in tune with the nature of art education and loaded with potential that echoes the spirit of early twenty-first century avant-garde. What makes Instagram particularly exciting is that it is easily available for everyone-and this is where the societal dimension of Brecht's epic theatre comes alive.

\section{Conclusions}

The reactions to Amalia Ulman's project Excellences \& Perfections as well as research on the impact of Instagram suggest that it might make sense to approach Instagram from the perspective of Verfremdung-in the art world as well as the art class. In a Brechtian sense this would mean an attitude of critical reflection while browsing one's photo feed and a creatively critical attitude to uploading content, perhaps in the form of reflexive meta-commentary or a take on acting techniques to achieve a Verfremdungseffekt. The most obvious thing in the world should call for explanation and be made to look strange, the spectator turned into an observer, and feelings can be replaced by reason, as Brecht has described. The principles for epic theatre present exciting possibilities when applied to social media.

Brecht wanted the spectators of his plays to see themselves as active members of society. The role of the narrative and elements of Verfremdung in epic theatre was to arouse a capacity for action. If art education 
aims to nurture active participation in visual culture, then perhaps a coupling of Brechtian theatre and social media makes sense.

Instagram is one platform that I have chosen to examine here. Other highly visual platforms with similar potential for self-expression might prove more popular in the future. Only in the past year, TikTok has rapidly become a favorite among younger teenagers and children with its 15 second moving image format. Nevertheless, Instagram currently remains the choice of powerful influencers and a site of everyday imagery across different age groups. Authenticity remains an expectation despite all we know and a lack of a critical distance-and playfulness with the premises - might be what affects the mental health of many. It could be interesting to look at a general TikTok aesthetic in a few years to see whether youth has taken social media in an entirely different direction.

I would like to conclude by presenting an art assignment that intervenes in the impulse to create more "fodder for the entertainment apparatus," to speak with Brecht, and inspires an imaginative approach to Instagram. The simple instruction is informed by artists who are using such instructions as Yoko Ono, Sol LeWitt, Peter Liversidge, and others who have created instruction pieces. It could be adapted to a group or read as an exercise for the imagination.

\section{Create Fiction on Instagram}

Make careful choices as if involved in a film production: cast, hair, make-up, costume, set design, lighting, shooting locations.

Upload a screenshot that shows how you work, filters and all.

Think of your audience as active members of society and choose hashtags accordingly.

Repeat and keep Verfremdung alive.

\section{Notes}

1. In opposition to the Aristotelian concepts of epic and dramatic writing, seen in this tradition as fundamentally different in character, Brecht talked about epic theatre. He also highlighted the educational aspect of the epic theatre, calling it theatre for instruction, as opposed to mere pleasure. This was the origin of his concept of the learning play (Lehrstücke) which explicitly addressed societal themes and the role of the spectator. 


\section{REFERENCES}

Bliokh, J. (Producer), \& Eisenstein, S. (Director). (1925). Battleship Potemkin [Motion picture]. Mosfilm.

Brecht, B. (1982a). Alienation effects in Chinese acting. In J. Willett (Ed. \& Trans.), Brecht on theatre: The development of an aesthetic (pp. 91-99). Hill and Wang.

Brecht, B. (1982b). Indirect impact of the epic theatre. In J. Willett (Ed. \& Trans.), Brecht on theatre: The development of an aesthetic (pp. 57-62). Hill and Wang.

Brecht, B. (1982c). The literarization of theatre (notes to the threepenny opera). In J. Willett (Ed. \& Trans.), Brecht on theatre: The development of an aesthetic (pp. 43-47). Hill and Wang.

Brecht, B. (1982d). The modern theatre is the epic theatre. In J. Willett (Ed. \& Trans.), Brecht on theatre: The development of an aesthetic (pp. 33-42). Hill and Wang.

Brecht, B. (1982e). The street scene. In J. Willett (Ed. \& Trans.), Brecht on theatre: The development of an aesthetic (pp. 121-129). Hill and Wang.

Brecht, B. (1982f). Theatre for pleasure or theatre for instruction. In J. Willett (Ed. \& Trans.), Brecht on theatre: The development of an aesthetic (pp. 69-77). Hill and Wang.

Brooker, P. (1994). Key words in Brecht's theory and practice of theatre. In P. Thomson \& G. Sacks (Eds.), Cambridge companion to Brecht (pp. 185-200). Cambridge University Press.

Brooker, P. (1998). Bertolt Brecht: Dialetics, poetry, politics. Croom Helm.

Brown, J. (2018). Is social media bad for you? The evidence and the unknowns. https://www.bbc.com/future/article/20180104-is-social-mediabad-for-you-the-evidence-and-the-unknowns.

Edmonson, T. (2015). Killing in the name. Texte zur Kunst, Heft 97. https:// www.textezurkunst.de/97/edmonson-killing-in-the-name/.

Fraser, A. (2005). Museum highlights: The writings of Andrea Fraser. MIT Press.

Gavin, F. (2014). Interview with Amalia Ulman. kaleidoscope.media/interviewamalia-ulman/.

Hegel, G. W. F., Miller, A. V., \& Findlay, J. N. (1977). Phenomenology of spirit. Clarendon Press.

Marx, K. (1964). Economic and philosophic manuscripts of 1844. International Publishers.

Miller, D. (2013). Future identities: Changing identities in the UK-The next 10 years. University College London.

Patterson, M. (1994). Brecht's legacy. In P. Thomson \& G. Sacks (Eds.), Cambridge companion to Brecht (pp. 273-287). Cambridge University Press. 
Royal Society for Public Health. (2017). Status of mind: Social media and young people's mental health and wellbeing. https://www.rsph.org.uk/uploads/ass ets/uploaded/d125b27c-0b62-4lc5-a2c0155a8887cd01.pdf.

Scherpe, M. (2011, February 1). Art in Berlin: Carson Chan. Stil in Berlin. https://www.stilinberlin.de/2011/02/interview-carson-chan.html.

Tavin, K., \& Tervo, J. (2018). How soon is now? Post-conditions in art education. Studies in Art Education, 59(4), 282-296.

Ulman, A. (2020). Amalia Ulman: Why I staged my own Instagram meltdown. What a fictionalised online performance revealed about the way we view women online. Financial Times, 3.1.2020.

Wagner, J. (2018). 'Stories' was Instagram's smartest move yet. https://www. vox.com/2018/8/8/17641256/instagram-stories-kevin-systrom-facebooksnapchat.

Weinstein, L. (Producer), \& Zucker, J. (Director). (1990). Ghost [Motion picture]. Paramount Pictures.

Open Access This chapter is licensed under the terms of the Creative Commons Attribution 4.0 International License (http://creativecommons.org/licenses/ by $/ 4.0 /$ ), which permits use, sharing, adaptation, distribution and reproduction in any medium or format, as long as you give appropriate credit to the original author(s) and the source, provide a link to the Creative Commons license and indicate if changes were made.

The images or other third party material in this chapter are included in the chapter's Creative Commons license, unless indicated otherwise in a credit line to the material. If material is not included in the chapter's Creative Commons license and your intended use is not permitted by statutory regulation or exceeds the permitted use, you will need to obtain permission directly from the copyright holder.

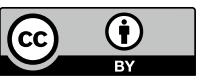

